\section{STRONG TEETH MAKE STRONG KIDS}

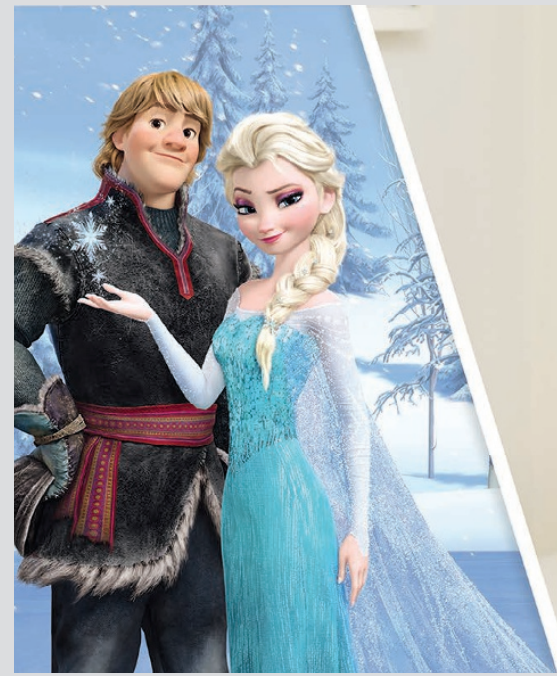

Oral-B is on a mission to support UK parents and carers to adopt appropriate home-based oral health behaviours and thereby reduce the number of children with toothache and dental problems - all through its \#StrongTeethMakeStrongKids campaign. The oral health experts from Oral-B and the University of Leeds, have launched a research and education programme to give dental professionals and parents the right support to prevent these dental health issues from now on.

'We are working closely with the UK's dental professionals by aiming to provide up to 20,000 dental professionals this year with simple and engaging educational materials for parents and their children during routine check-ups. Oral-B is committed to take on this challenge to sustainably improve the situation in the UK', says Jane Kidson, Oral-B Professional Team Leader UK and Ireland.

Combined with the right dental care products, these positive oral health messages

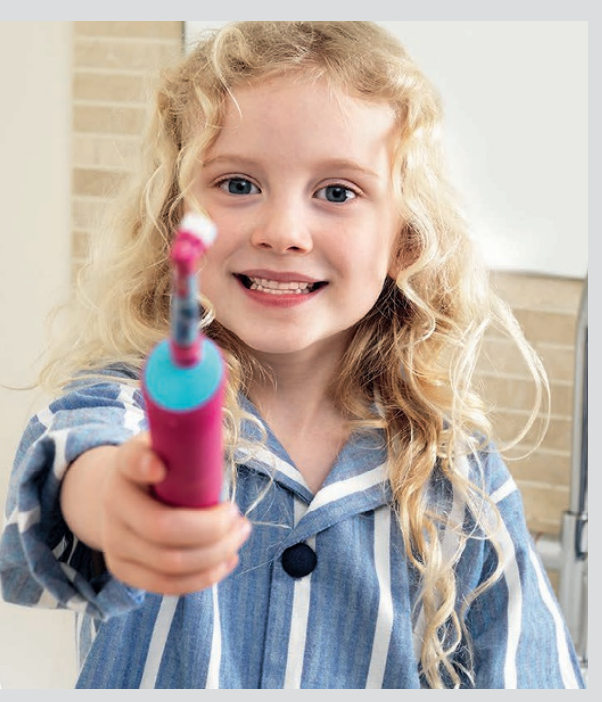

are designed to encourage parents to lead the way, so they can see that these oral health issues are mostly preventable with simple changes to their families' daily oral care routine.

Here is a snapshot of the brand's educational materials that dental professionals can use to support the conversations that they are having with parents and carers:

1. Brushing from first tooth to five years

2. Friends and family can support healthy habits

3. Make brushing fun for children

4. Healthy eating can help protect teeth.

Maintaining good oral health and establishing the right healthy habits early on will help children progress along the key 'Strong Teeth' milestones. They include their first dental visit, the arrival of their first tooth or teeth, and then the first time they use an electric power toothbrush (from the age of three onwards).

\title{
NEW OPPORTUNITIES FOR EVERYBODY TO CAMPAIGN FOR BETTER ORAL HEALTH
}

The Oral Health Foundation has

relaunched its website, with the focus on giving its supporters more opportunities to be actively involved in raising awareness of important causes.

The new online platform not only allows visitors to support all the charity's campaigns and activities, such as National Smile Month, but also gives many more the chance to participate in them. The website also houses its own dedicated fundraising platform, which means that individuals and groups can create and share their own fundraising efforts and raise money for a series of charitable causes related to oral health.

Visitors can also read about the latest oral health news, take an interest in a series of new blogs and read the charity's digital magazine.

The redesigned website is live now at www.dentalhealth.org.
DENTAL PARTNERS: MAKING A DIFFERENCE WITH DENTAID

Dental Partners is a growing network of practices with an ethos of supporting its staff and charities operating within the dental sector. The opportunity to combine both these aspects of support presented itself last month when Jess Hague, a dental nurse from one of its latest acquisitions, High Green Dental Practice in Sheffield, became a volunteer for Dentaid.

As one of the world's leading oral health charities, Dentaid's vital work involves supplying refurbished dental surgeries and oral healthcare to projects in many different countries. This includes sending teams of volunteer dental professionals from the UK to countries where there is an acute shortage of dental care across a variety of settings including schools, prisons, orphanages and refugee camps.

Along with three volunteer dentists, Jess spent a week in May at a Syrian refugee camp on the Greek island of Samos, where she helped refugees who had no access to dental care. The team provided vital dental treatment along with toothbrushes and oral health products.

Jess said: 'I've never experienced anything like this before, seeing so many people in desperate need of dental treatment - it really opened my eyes to the amazing work Dentaid's volunteers do.'

Find out more about Dental Partners at www.dentalpartners.co.uk or email contact@dentalpartners.co.uk.

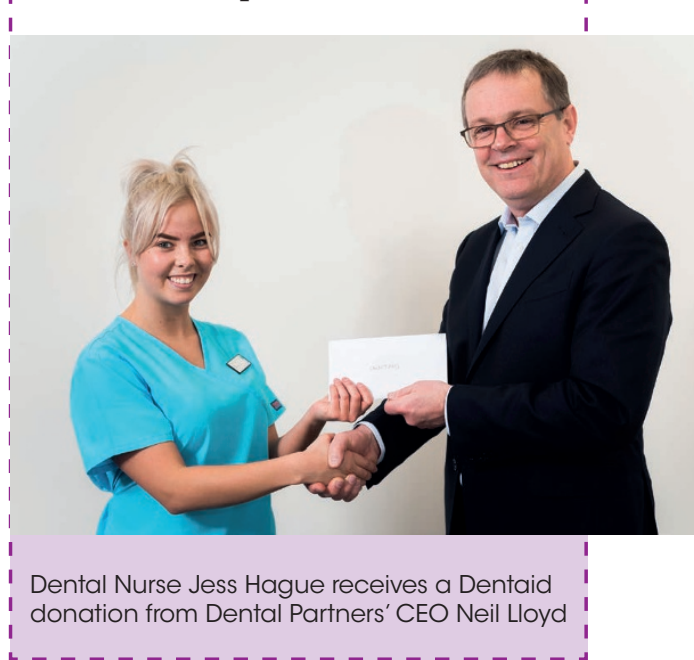

